\title{
Maytansine-Site Binding Agent
}

National Cancer Institute

\section{Source}

National Cancer Institute. Maytansine-Site Binding Agent. NCI Thesaurus. Code C67477.

Any of a class of anti-mitotic compounds that bind to the maytansine site of the beta tubulin subunit, a region that appears to overlap, at least partially, with the vinca-binding site. Compared to the vinca-site binding agents, these ligands have distinctly different chemical structures, resulting in unique interactions with the sulfhydryl residues, and perhaps with other structures on the tubulin protein, thereby producing different physiological effects which do not fully mimic those of the vinca-site ligands. Like the vinca-site agents, these compounds inhibit the polymerization of tubulin dimers and thereby, prevent the assembly of microtubules. The subsequent decrease in the amount of formed microtubules causes disassembly of the mitotic spindle resulting from instability of the structure during the mitotic interphase, eventually leading to cell cycle arrest and/or apoptosis. 